\title{
Australian Undergraduate Information Systems Curricula: a comparative study
}

\author{
Joan Richardson \\ RMIT University \\ Melbourne, Australia \\ Frada Burstein \\ Monash University \\ Melbourne, Australia
}

joan.richardson@rmit.edu.au

Ana Hol

Western Sydney University

Sydney, Australia

Rodney J Clarke

University of Wollongong

Wollongong, Australia

frada.burstein@monash.com.au

Jim M McGovern

RMIT University

Melbourne, Australia

A.Hol@westernsydney.edu.au

\author{
rclarke@uow.edu.au
}

jim.mcgovern@rmit.edu.au

\begin{abstract}
The paper describes the first comprehensive comparative study of undergraduate Information Systems (IS) degree programs in Australia using the model curricula outlined in ACM/AIS IS2010 as a reference point. The study had three broad aims: 1) to compare the Australian IS curriculum with that of other major IS education systems internationally, 2) to identify what subject areas are considered mandatory and what are considered optional in Australian IS programs, and 3) to understand if the host academic division within different disciplines (e.g. Business or Science/Engineering/Information Technology) has an influence on the variations in the subject areas offered. In a first phase, 2017 IS degree program data was obtained from university websites. In a second phase, this data was validated in consultation with academic staff from those universities offering the programs. The conclusion is that a high level of adherence to the IS2010 curricula was evident in core courses; considerable diversity was found in a long tail of non-core offerings; and the location of the host academic unit within Business or Science/Engineering/Technology influenced the subject areas offered.
\end{abstract}

Keywords: IS2010. Information Systems Curricula, Computing Education,

\section{Introduction}

Information Systems (IS) academic programs first began to appear in the early 1970's, and the Association of Information Systems (AIS), the major US professional body, was only established in 1994 [2]. The IS academic discipline sits within the wider field of Information Technology (IT) along with disciplines, such as, computer science and computer systems engineering, and is broadly described as lying at the juncture of organisations (or business) and technology. Within Australian universities, the IS education function is primarily placed in Business, or in Science, Engineering \& Technology (SET) academic divisions, though it is also taught in other domains, including the humanities.

The work leading to the previous significant revision of Australian IS curriculum took place more than ten years ago, and, in a rapidly changing field, this alone is an important reason to re-evaluate the curriculum [7]. At a time when the interest in studies in Information Systems 
has significantly declined and the field is attempting to reverse this trend, this research represents a starting point of an effort to re-evaluate the core principles of the discipline through a more detailed analysis of just what is being delivered under the banner of IS. The work undertaken served to engage the IS academic community, and the profession as a whole to inform a shared understanding of curriculum. What is taught in IS academic programs, in part, defines the discipline [11] and distinguishes it from other areas of IT. It is important for the IS academic community and for the IT profession as a whole that curriculum is understood and examined in a global context.

This study examined the undergraduate IS curriculum in Australia with three broad aims: $1 /$ to compare the Australian IS curriculum with that of other major IS education systems 2/ to identify what subject areas are considered mandatory (core) and what are considered optional in Australian IS programs, and 3/ to understand what influence, if any, placement in Business or SET academic divisions have on program content.

Curriculum studies can take a descriptive approach, what is actually taught, or a normative approach, or what should be taught. This study will be primarily descriptive, though it will draw on normative approaches in comparing curricula with standard models.

\section{Information Systems Body of Knowledge}

Globally, a number of professional bodies define the required knowledge and skills of Information Technology (IT) practitioners and by implication what should be taught in the academic programs that prepare these professionals. In Australia, Information Systems (IS) curriculum is driven to a large degree by the Australian Computer Society (ACS). The ACS Core Body of Knowledge (ACSBoK) [1] guides professional certification for IT professionals as well as accreditation of academic programs. Almost all IS majors provided by publiclyowned universities are accredited at the professional level. ACSBoK links to the global IS community in referencing the international framework Skills for the Information Age (SFIA) [12]. In the UK, the British Computer Society [3] performs a similar role to the ACS working with the UK QAA [16], which provides Subject Benchmarking Statements in the area of Computing [16]. In the US, the Association for Computing Machinery/Association for Information Systems (ACM/AIS) has developed a set of model curricula including IS2010 [14] that addresses undergraduate IS programs, and MSIS2016 [15] that addresses graduate programs. In Europe, the European Foundational ICT Body of Knowledge has been developed $[5,6]$.

Of these, only the ACM/AIS IS2010 specifically targets IS undergraduate education, identifying and spelling out in detail seven (7) core IS courses (subject areas) in a model curriculum. Adding weight to the ACM/AIS IS2010 as a de facto global IS standard, the latest UK QAA Subject Benchmarking Statements for Computing [16] defers to the ACM IS2010 standard indicating that "...[ACM/AIS] documents are recommended to inform program design and curriculum content”. IS2010 would appear to be a good candidate for a reference curriculum. It is used in the US and UK, specifically addresses the undergraduate IS curriculum, and provides a model of core subjects, and examples of non-core subjects, with full topic lists and descriptions.

Particular IS programs are designed for different academic environments with their own imperatives and views as to what knowledge and skills are important and required by graduates in 3-5 years. Different programs may uniquely package topics into units of delivery, and a variety of unit titles are used, even for similar or overlapping material. Two methods can be used to make comparisons, a topic-based approach in which units (of delivery) can be unpacked down to the topic (knowledge unit, skill or competency) level, or a subject-based approach where units can be broadly classified according to some common reference subject area, or typical grouping of topics. While the former method may be more accurate, it creates considerably greater effort in determining standard topics, and classifying, storing and processing them. This study employs a more pragmatic, subject-based approach, making use of the subject areas defined by IS2010 as a point of reference. 


\section{ACM/AIS IS2010 Model Curriculum}

IS2010 describes a model curriculum of 7 core IS courses (subjects / units) providing detailed syllabuses for each of the following semester-subjects:

- Foundations of IS (IS2010.1)

- Data and Information Management. (IS2010.2)

- Enterprise Architecture (IS2010.3)

- IS Project Management (IS2010.4)

- IT Infrastructure (IS2010.5)

- $\quad$ Systems Analysis \& Design (IS2010.6)

- Strategy, Management, and Acquisition (IS2010.7)

The topic list for each subject facilitates classification of units of delivery. IS2010 provides for a capstone course and encourages consideration of electives and specialisation for career tracks. The reduction of the core from ten (10) to seven (7) core courses is a major change from IS2002, encouraging greater flexibility, particularly in enabling career tracks. The reduced number of core courses has impacted on program designs by flattening the pre-requisite structures [10]. IS2010 also provides a list of possible model electives [14]:

- Application Development

- Business Process Management

- Collaborative Computing (listed, but not specified in detail)

- Data Mining/Business Intelligence (listed, but not specified in detail)

- Enterprise Systems

- Information Search and Retrieval (listed, but not specified in detail)

- Introduction to HCI

- IT Audit and Controls

- IS Innovation and New Technologies

- IT Security and Risk Management

- Knowledge Management (listed, but not specified in detail)

- Social Informatics (listed, but not specified in detail)

\section{IS Program and Curriculum}

In the UK, Stefanidis and Fitzgerald [13] studied IS curriculum, examining 806 modules (units) from 43 undergraduate IS degree programs offered by 13 universities in the Greater City of London. They classified modules into the 16 UK QAA Subject Benchmarking Statement Computing Body of Knowledge descriptors in operation at the time ${ }^{1}$. The most common categorisation of core modules occurred in Data, Information \& Knowledge Management (offered in 98\% of programs) and Development, Implementation \& Maintenance of IS (93\% of programs). There were no modules offered in the categories of Compression Technologies, Content Management Systems, Personal Information Systems and Digital Libraries. 18\% of core modules could not be placed in any of the 16 categories. Only four subject areas appeared in all studies: Programming, Database, Data Communications, and Systems Analysis \& Design. IS Concepts was the next most commonly cited subject area.

Hwang, Ma \& Wang $[8,9]$ studied the alignment of IS programs with IS2010 in the US, examining 2229 courses (units) from 394 undergraduate IS programs. Their sample included the Association to Advance Collegiate Schools of Business (AACSB) accredited programs, non-AACSB accredited programs, private and public providers, and $\mathrm{PhD}$ granting and nonPhD granting institutions. They found that Data \& Information Management (IS2010.2), along with Systems Analysis \& Design (IS2010.6), were the most common units offered as core. Units with a development focus: Programming Language, Application Development and Web Development, were the most commonly offered subjects areas from outside the IS2010 model

\footnotetext{
1 The UK QAA Subject Benchmarking Statement was updated in 2016.
} 
core. They also found that $27.4 \%$ of programs offered units in subject areas that were outside of the IS2010 model core and the top 9 non-IS2010 subject areas.

Also in the US, Bell Mills \& Fadel [4] examined the alignment of 127 undergraduate IS programs from AACSB accredited Business schools with the ACM/AIS IS2010 model curriculum. The results were of a similar order in both studies, though there were statistically significant differences (these results are shown later in Table 4). A simple comparison of means using a $\mathrm{z}$ test $(\mathrm{P}<=0.05)$ on the two samples indicated no significant difference in the adoption of Systems Analysis \& Design (84\% and 80\%), and Enterprise Architecture (17\% and 14\%), but indicated that the results of the Adoption of the IS2010 Curriculum Guidelines review of AACSB programs was significantly higher for Data \& Information Management (97\% vs 87\%), Foundations of IS ( $87 \%$ vs $63 \%$ ), IT Infrastructure (70\% vs 32\%), and Strategy, Management, and Acquisition (29\% vs 16\%). The larger more general IS2010 alignment study of Hwang, Ma, \& Wang, [8, 9] found a significantly higher take up for IS Project Management (29\% vs 16\%). It would appear that AACSB programs (the Bell, Mills \& Fadel study[4]) had higher IS2010 adherence rates at least in some subject areas. However, Hwang, Ma \& Wang [8, 9] found no significant difference overall between adoption by AACSB and non-AACSB programs. The AACSB-only IS2010 alignment study [4] also examined the level of adherence to the full requirement of IS2010, finding that only 2 programs included all 8 courses ( 7 courses + capstone) with 77\% having 3-5 courses. On average, the alignment of IS2010 core units by the programs surveyed was 3.4 from the 7 possible units of the IS2010 model core.

With respect to the core subjects offered by programs that were not specified as part of the IS2010 model, the findings of the two US studies were also similar. Application Development (Programming/Application Development) was the most common subject category, being present in at least $70 \%$ of programs. Web Development was the next most commonly occurring requirement in up to a third of programs. In both US studies, E-Commerce (E-Commerce/ Mobile), Business Intelligence (Business Intelligence \& Analytics), Cybersecurity (IS Security) were found to be core requirements in less than 1 in 6 programs $[4,8,9]$.

Hwang, Ma \& Wang [8,9] and Bell, Mills \& Fadel [4] reported studies that collected data in 2011, soon after the introduction of IS2010, and perhaps too early for the new model to influence programs. Yang [17] conducted a similar study of 234 IS programs offered by US AACSB accredited schools more recently, in late 2015. The findings were not significantly different to those of the other AACSB-based study of Bell, Mills and Fadel [4] in 6 of the 7 subject areas. The exception was the unit Enterprise Architecture, which Yang [17] found to be required core in only $3 \%$ of programs as compared to the $14 \%$ and $17 \%$ of the other two studies. Yang also concluded that collectively the AACSB IS programs implemented a core that focused on: Data \& Information Management, Systems Analysis \& Design, Foundations of IS and IT Infrastructure from the ACM/AIS IS2010 model core, with the addition of Application Development [17].

The three US studies $[4,8,9,17]$ described above collected data from readily available web sites and online catalogues. In addition, Bell, Mills \& Fadel [4] followed up their data collection with interviews at a sub-set (a calculated sample size) of heads of programs to validate the collected data, but also to assess perceived adherence against their measured adherence. Interestingly, they found that perceived adherence was significantly higher than their observed adherence.

In the Australian context, a comprehensive analysis of the state of the IS discipline was conducted in 2006, identifying 46 areas of IS activity across 37 Australian universities ${ }^{2}$ [7]. The influence of both business and technology is evident, with IS professional education being managed by Business (25 programs), Science, Engineering and Technology (12 programs) and Information Technology (4 programs) academic divisions. In some cases, multiple IS programs existed in the one institution, with one or sometimes more in Business academic divisions and one or more administered by SET-based academic divisions. The study addressed distinctive features of the IS curriculum, but the focus was on breadth rather than depth, and the findings described a flavour rather than consistent curriculum design, detailed quantitative data [7].

2 They included two private universities, Bond University and Notre Dame, but not Charles Darwin University. 


\section{Method}

All 36 publicly owned Australian universities were included in the study. Only those undergraduate IS majors that had an intake in 2017, were analysed. This study followed the approach of Bell, Mill \& Fadel [4] collecting data in two phases, an initial data collection phase and a subsequent data validation phase where appropriate academic staff from those universities that provided the IS programs were consulted.

In the first phase of the study, IS program data, unit offerings and their location within the university structure was obtained from publicly accessible websites. In most cases, there appeared to be enough up-to-date information to provide a reasonable basis for analysis. Further searches were often able to reveal more detailed information, if needed. The identification of IS programs is not always straight-forward. In many cases, titles were clear, but in some cases, particularly in major areas of study such as Software Development, judgment was required. In general, where program titles indicated IS or IS Development and associated professional roles, they have been included.

A subject-based approach in which a reference list of subjects is the basis for classifying units offered in the various IS programs was used to map units to subject areas. The reference list was initially constructed from the IS2010 model core and IS2010 example electives [14]. After a pass of units offered, the IS2010 example elective Data Mining/ Business Intelligence was replaced on the reference list by two more commonly occurring topic groupings (at least in the Australian context): Data Analytics/Data Mining and Business Intelligence/Data Warehousing. When offered units were encountered, that did not match existing subject areas on the reference list, additional subject area descriptions based on these units were added to the reference list.

In very few cases do unit descriptions exactly match subject descriptions on the reference list, and units were classified more in terms of capturing the "spirit" of the standard in its aims, the level of the offered unit, as well as the inclusion of important topics. In essence, the reference subjects are intentionally referred to as subject areas and treated more as categories. The absence of a match with a subject area in the reference list does not mean that topics are not covered, but rather that there is no single identifiable unit that can be argued to focus on the content of the reference subject area. Overall, 140 distinct subject areas were used to describe the offerings in this study. The first phase was conducted over several months in early 2017 producing mappings of units offered for each IS major to the reference list of subject areas.

In a second phase conducted in late 2017, all IS providing universities identified in the first phase were consulted to verify the selection of IS programs, and the classification of unit offerings. Heads of IS programs were contacted and generally access was given to an academic staff member with detailed knowledge of the program, typically a program coordinator or director. The preliminary analysis (mappings) of their programs and the list of reference subjects were distributed to these academic coordinators and feedback sought, in most cases through phone conversations. The final decision on whether or not a particular major was an IS major, and how units should be mapped to subject areas was left to the program coordinators. In the consultation phase, two programs were removed, one was added, and a number of revisions were made to the lists of core and non-core IS units offered.

The approach used in this study required interpretation of high level catalogue entries and the classification of units into subjects areas based on a $50 \%+$ match reference subjects. This means some subject areas may be covered in total across the curriculum, but have not been included in any particular item. A focus on topics, without consideration of their packaging into delivery units, may provide a slightly different picture. While some classifications are clear and agreed, some required subjective judgment, and other assessors may have made different classifications. In the consultation phase, the final arbiters of unit classification were the program coordinators.

\section{Data Analysis in the Australian Context}

The subject-based approach based on the ACM/AIS IS2010 model and the methods used by Hwang, Ma \& Wang [8, 9], Bell, Mills \& Fadel [4] and Yang [17] provides a practical guide to assessing large numbers of programs. It also enabled the Australian IS academic community to 
compare their programs to those of the US. In addressing its overall aim, this study uses a similar subject-based approach (as outlined in the method section above) to address the following specific questions in the Australian context:

- Where are IS academic programs placed in terms of academic divisions?

- What are the core IS units delivered in IS programs?

- How does the delivered core align with IS2010?

- What non-core IS units are offered in Australian IS programs?

- How does the level of alignment with the IS2010 core in Australia compare with that of US studies?

\subsection{Academic Programs Placement in Academic Divisions}

Of the 36 universities in the study, 6 did not offer an undergraduate IS major. From the remaining 30 Universities deemed to have undergraduate IS majors, 32 different academic organisational divisions administered the selected programs. Only in one case did different divisions from the same university provide undergraduate IS majors relatively independently. Figure 1 illustrates the location of the vast majority of undergraduate IS majors in SET or Business divisions. Twenty-eight (28) of the 32 academic divisions were split evenly between these divisions. Three additional SET focused divisions contained the term Information Technology, Information Science or Computing in their title. There was only 1 high level division (a faculty) dedicated to Information Technology. Twenty four (24) of these main academic units were further divided into Schools, Departments or Discipline groups.

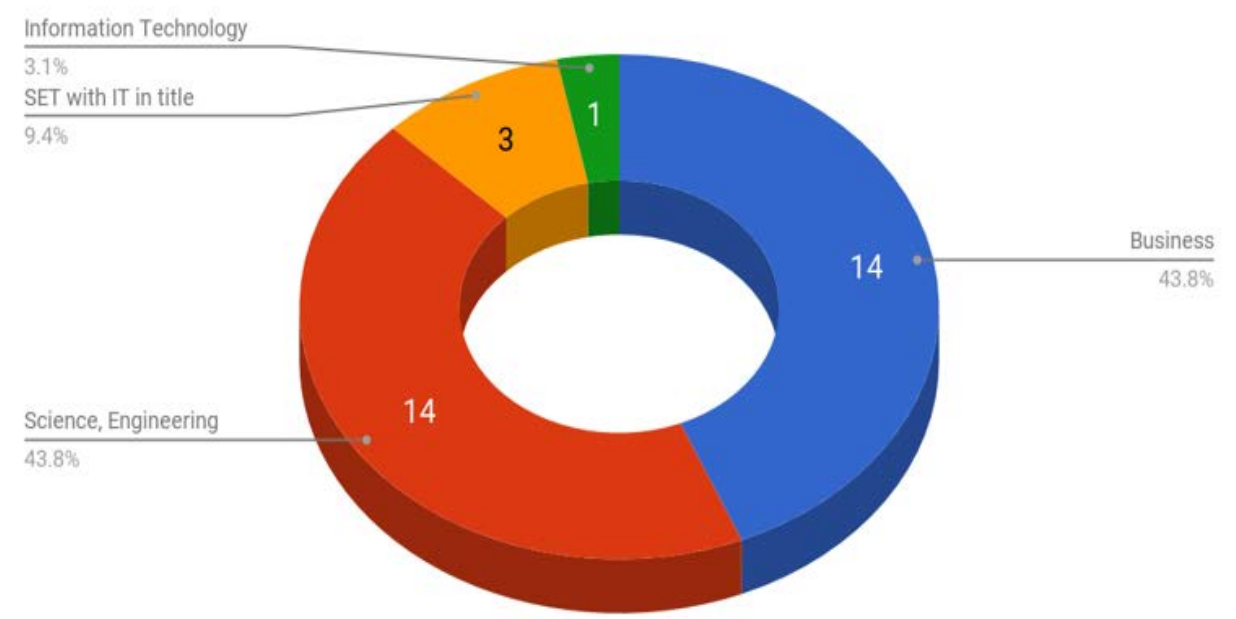

Fig. 1. Administering Academic Divisions

IS continues to be offered across Business and SET focused academic divisions in Australia, though there has been some change since The Information Systems Discipline in Australia study reported in 2008 [7]. IS programs administered by Business academic divisions decreased from 25 to 14, while those administered by SET have increased from 8 to 17. The number of dedicated first level IT academic divisions has decreased from 4 to 1 . The increased presence of IT in some division titles, primarily SET, may be a result of the merging of dedicated first level IT academic divisions into other SET-based academic divisions.

\subsection{Core IS Subject Areas}

From the 30 universities, 49 IS majors were identified. Of these 49 IS majors, 1 university had 4 majors, 3 universities had 3 majors each, 10 had 2 majors each and 16 had a single IS major. Of the 14 universities that had multiple majors, 8 of these had discernible "Y" structure, where a common core accommodated mostly 2 but also 3 streams. These 49 majors were further collapsed into 33 distinct programs. An IS program is defined as one or more majors designed and managed by the same group of academic staff. For example, a "Y" structure with the same 
stem and different branches would be classified as a single program, where units offered were counted once only. Table 1 shows the subjects required as core in 5 or more programs.

Table 1. Units Required as Core in Australian undergraduate IS programs

(ACM/AIS 2010 Model core is shown in bold italics)

\begin{tabular}{|l|r|r|}
\hline Subject Category & Count & \multicolumn{1}{|c|}{$(\mathbf{n}=\mathbf{3 3}$ ) } \\
\hline Systems Analysis \& Design (IS2010.6) & 32 & $96.97 \%$ \\
\hline Data \& Information Management (IS2010.2) & 31 & $93.94 \%$ \\
\hline Fundamentals of Programming & 26 & $78.79 \%$ \\
\hline Foundations of IS (IS2010.1) & 25 & $75.76 \%$ \\
\hline IS Project Management (IS2010.5) & 23 & $69.70 \%$ \\
\hline Professional Skills (General, incl ethics) & 15 & $45.45 \%$ \\
\hline IT Infrastructure (IS2010.4) & 15 & $45.45 \%$ \\
\hline Data Communications \& Networking & 15 & $45.45 \%$ \\
\hline Web Applications/Technology & 12 & $36.36 \%$ \\
\hline IS Project (Single Unit) & 11 & $33.33 \%$ \\
\hline IS Project (Double Unit) & 11 & $33.33 \%$ \\
\hline Strategy, Management, and Acquisition (IS2010.7) & 10 & $30.30 \%$ \\
\hline HCI & 9 & $27.27 \%$ \\
\hline Professional Skills (Communication) & 8 & $24.24 \%$ \\
\hline Business Process Management & 7 & $21.21 \%$ \\
\hline Enterprise Systems (ERP) & 6 & $18.18 \%$ \\
\hline Business Analytics Foundations/ Business Stat Methods & 6 & $18.18 \%$ \\
\hline Application Development & 6 & $18.18 \%$ \\
\hline IT Security \& Risk Management & 5 & $15.15 \%$ \\
\hline E-Commerce & 5 & $15.15 \%$ \\
\hline Business Intelligence/Data Warehousing & 5 & $15.15 \%$ \\
\hline
\end{tabular}

Units offered were divided between those that were core to a program and those that were not core (non-core). Core units are those units that must be completed by all students doing any of the IS majors in a particular program. In essence, core units are needed by all graduates, and are compulsory in all majors within a program. Non-core units are those units that are elective or not core to all majors. In total, 648 IS unit offerings were identified across the 33 programs, 365 core units and 283 non-core units. Each of these units was classified according to the best match (at least 50\%) in the reference list of subject areas. The 365 core units were collapsed into 68 distinct subject areas, and the 283 non-core units into 113.

Placement within Business or SET appears to have an impact on the size of the IS core. The 19 SET-placed programs required 233 core IS units over 63 distinct subject areas, with an average of 12.3 core units per program. The 14 business-placed programs required 126 core IS units over 38 distinct subjects area, an average of 9 core IS units per program. For non-core, the differences are not so marked. The SET-placed programs offered 162 IS units over 91 distinct subject areas, an average of 8.5 non-core IS units/program, and the business-placed programs offered 106 IS units over 61 distinct subjects areas, an average of 7.6 non-core IS units per program.

The location of IS program within the university structure also appears to have an impact on the types of units offered and therefore on the skills of the graduate. SET-placed programs have higher levels of technical content as core, while business-placed programs require more business focused subject areas.

For 15 of the top 22 core subject areas, there is no significant difference (at $\mathrm{P}<=0.05$ level) in adoption by Business and SET placed programs. For the other 7 subject areas, Fundamentals of Programming, HCI, Data Communications \& Networking, IS Project Management (IS2010.5) and IT Infrastructure (IS2010.4) were more often core in SET-managed programs, while Business Process Management and Business Intelligence/Data Warehousing were more often required as core in Business-managed programs. 


\subsection{Alignment with IS2010 Model Core}

Units that correspond to the IS2010 core model subject descriptions, Systems Analysis \& Design (IS2010.6) and Data Information \& Management (IS2010.2) are required in almost all of the 33 IS programs, 32 and 31 respectively. Foundations of IS (IS2010.1) and IS Project Management (IS2010.5) are required in a majority (25 and 23) of programs. IT Infrastructure (IS2010.4) is required in 15 programs, Strategy, Management, and Acquisition (IS2010.7) in 10 programs, and Enterprise Architecture (IS2010.3) is a distinct unit in only 2 programs.

Of the non IS2010 subject areas commonly required as core, Fundamentals of Programming appears in a majority of programs, 26 of 33. Data Communications \& Networking is required in 15 programs and Web Applications/ Technology in 12 programs. Units identified as HCI, Enterprise Systems (ERP), Business Analytics Foundations/ Business Statistical Methods, Application Development, Business Process Management, IT Security \& Risk Management, E-Commerce, and Business Intelligence/Data Warehousing are required in between 5 and 10 of the 33 programs.

Figure 2 shows that most of the surveyed universities have core units of delivery that align with over half of the IS2010 model core subject areas, with a normal-type distribution of around 4 subjects areas in the core. No university adopted all IS2010 core subjects and only 3 programs required less than 3 subjects from the IS2010 core.

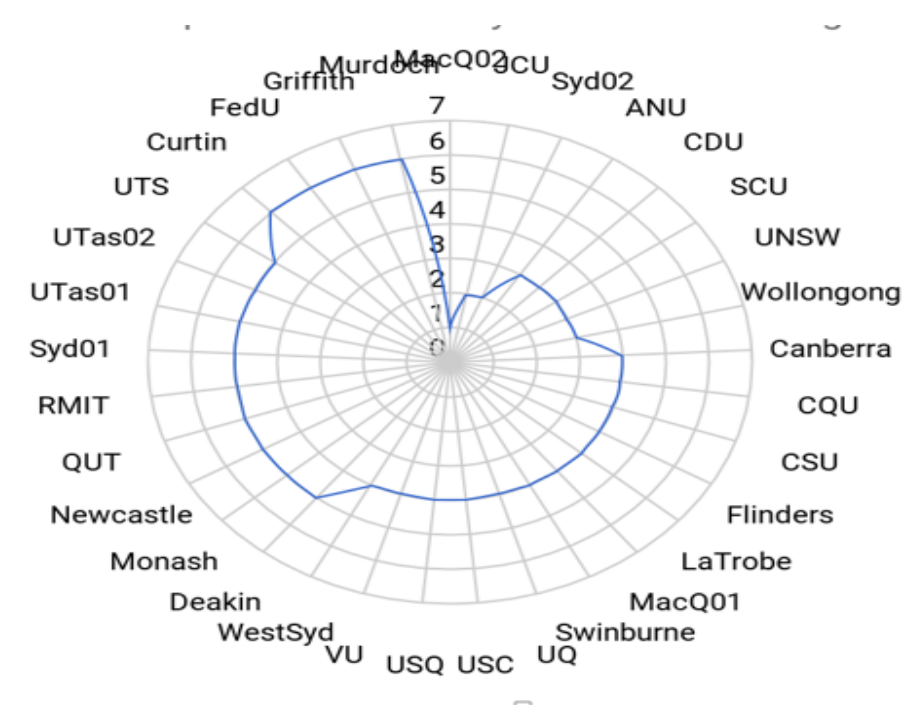

Fig. 2. Adoption of IS2010 by Australian IS programs

Overall, Australian IS programs have an average core adoption of 4.2 of the 7 core IS2010 subjects, compared to 3.4 from 7 found in the US [8, 9]. SET-placed programs (average of 4.6) have significantly higher alignment than Business-placed programs (3.8).

\subsection{Non-Core IS Subjects offered in Australian IS programs}

Figure 3 shows the prevalence of IS-related subjects classified as non-core. From the IS2010 model core, Strategy, Management, and Acquisition - IS2010.7 (10 of 33), IS Project Management - IS2010.5 (6), Enterprise Architecture - IS2010.3 (4), Data \& Information Management - IS2010.2 (2), and Foundations of IS - IS2010.1 (1) are offered as non-core. Outside of the IS2010 core, Application Development (Mobile), Data Analytics/Mining, IT Security \& Risk Management, Enterprise Systems (ERP), Application Development (Web), Business Intelligence/Data Warehousing and Business Analytics Foundations/Business Statistical Methods appeared in 6 to 10 of the 33 programs. 


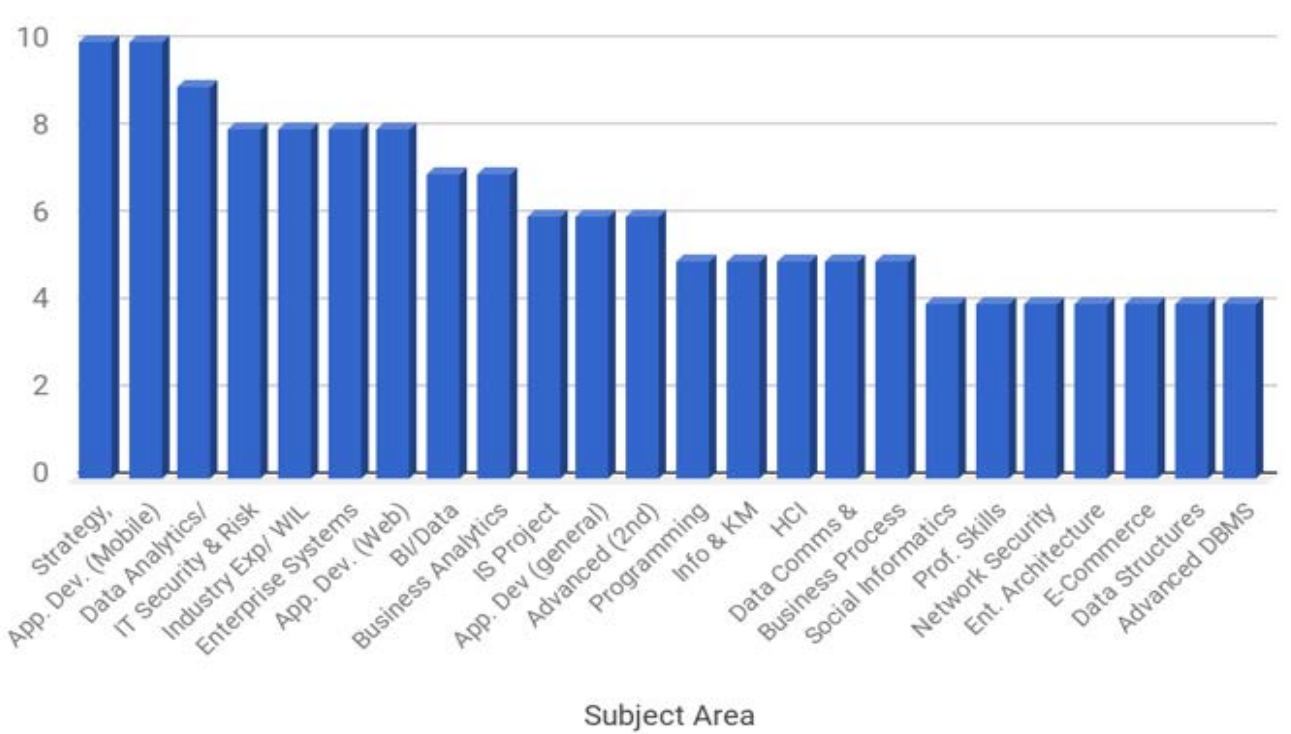

Fig. 3. Non-Core IS Subjects

There is a long tail of 89 non-core subject areas offered in less than 4 programs. 53 subject areas are offered in only one program. Notable IS subject areas in this tail include: Web Applications/Technology, IS \& Cloud Computing, Accounting Information Systems, Social Informatics, IT Management, IS Innovation, Global IS, and Health Informatics. A number of subjects areas cover more advanced topics in areas of specialisation, such as: Business Analysis, Application Development (Mobile), Application Development (Web), Data Analytics, Game Technology \& Development, and Business Process Management. A small number of programs provide options in the area of professional skills (consulting, organisational behaviour, communication for English as a second language) and capstone activities (subjects and projects). The most common non-core capstone was actual industry experience, no doubt indicating the selective nature of industry placements.

There is significant difference in their level of adoption by Business-placed and SETplaced academic divisions in 5 of 24 non-core subject areas. Application Development (Web) and Social Informatics were more likely to be offered by SET-based programs as non-core, while IS Project Management (IS2010.5), Data Communications \& Networking, and Business Process Management are more likely to be offered as non-core in Business-based programs.

Forty-seven (47) non-core subject areas are offered by less than 5 programs. Twentyfour (24) subject areas are offered by only 1 program. This long tail includes niche and emerging areas of IS, and different ways of offering professional skills learning and capstone experiences. Niche and emerging IS subjects areas include: Data Analytics/ Data Mining (3 of 33), Social Informatics (2), IT Audit \& Control (2), IS Innovations (2), Decision Support Systems (2), Service Management \& Customer Support (2), Introduction to Games Technology \& Development (1), and IS \& Cloud Computing (1). Unique capstone activity included Industrial Placement Experience (4) and IS capstone activity delivered more in the form of a classroom experience (3). Relatively unique dedicated professional skills units included problem solving skills (3), working in industry (1) and collaboration and teamwork (1). Overall, these results indicate more diversity than that found in the US. In Australia, the proportion of units, 62\% (227 of 365) classified into subject areas outside of the IS2010 model core is significantly higher than the 37\% (820 of 2227) found by Hwang, Ma and Wang [8, 9].

\subsection{Comparison of IS2010 Alignment in Australian and US Studies}

Table 2 compares the IS2010 core subjects required in this study with those required as core in the US studies of Hwang, Ma \& Wang [8, 9] and Bell, Mills \& Fadel [4]. Overall, the results are of a similar order, though there are some significant statistical differences (at $\mathrm{P}<=0.05$ level). There are no significant difference in the core requirement for Data \& Information Management (IS2010.2) and Enterprise Architecture (IS2010.3). Adoption of Systems Analysis \& Design (IS2010.6) in Australia was significantly higher than that found in 
both US studies, while IS Project Management (IS2010.5) and Strategy, Management, and Acquisition (IS2010.7) had higher adoption than that found in only one of the US studies. Foundations of IS (IS2010.1) and IT Infrastructure (IS2010.4) had significantly lower levels of adoption than that found in the US AACSB focused study [4]. Data Communication is required core in almost half of Australian programs (45\%), compared to only 5\% of US programs and it is likely that this subject area obviates the need for the IS2010 subject IT Infrastructure (IS2010.4) which includes a substantial number of data communications and networking topics.

The UK study reported in 2010 [13] does not use the IS2010 model as a reference and a comparison of all subject areas cannot be made. However, in the subject areas of Data \& Information Management, and IT Infrastructure, there are similar levels of adoption.

Programming and application development units are not part of the IS2010 model core, but are still widely required as core in Australia, the US and the UK. Units that build on a first programming unit for application development in general, mobile applications and web applications are also common in the curriculum. Gaming is beginning to appear as an option in IS programs, possibly as a vehicle for IS development skills, including analysis, design, HCI, and programming. In the UK and Australia, the professional bodies with their focus on the broader IT professional, may influence this, but the IS2010 core includes no recommendation around programming, suggesting that academic program designers still consider programming and development as central to the IS discipline.

Table 2. Comparison of Core Subject Area: Australia, US and UK

\begin{tabular}{|l|r|r|l|l|l|l|}
\hline \multicolumn{1}{|c|}{ Subject Category } & Count & $\begin{array}{r}\text { \% } \\
\text { (n) 33) }\end{array}$ & $\begin{array}{l}\text { US } \\
\text { AACSB }\end{array}$ & $\begin{array}{l}\text { Hwang } \\
\text { et al } \\
\text { US [9] }\end{array}$ & $\begin{array}{l}\text { Stefanidis \& } \\
\text { Fitzgerald } \\
\text { [13] }\end{array}$ & UK BoK $\mathbf{B}^{\mathbf{2}}$ \\
\hline $\begin{array}{l}\text { Systems Analysis \& } \\
\text { Design (IS2010.6) }\end{array}$ & 32 & $97 \%$ & $84 \%$ & $80 \%$ & $60 \%$ & IS Design \\
\hline $\begin{array}{l}\text { Data \& Information } \\
\text { Management (IS2010.2) }\end{array}$ & 31 & $94 \%$ & $97 \%$ & $87 \%$ & $98 \%$ & $\begin{array}{l}\text { Data, Information } \\
\text { \& Knowledge } \\
\text { Mgmt. }\end{array}$ \\
\hline $\begin{array}{l}\text { Foundations of IS } \\
\text { (IS2010.1) }\end{array}$ & 25 & $76 \%$ & $87 \%$ & $63 \%$ & $>50 \%$ & No single category \\
\hline $\begin{array}{l}\text { IS Project Management } \\
\text { (IS2010.5) }\end{array}$ & 23 & $70 \%$ & $38 \%$ & $66 \%$ & $93 \%$ & $\begin{array}{l}\text { Implementation \& } \\
\text { Imtce. }\end{array}$ \\
\hline $\begin{array}{l}\text { IT Infrastructure } \\
\text { (IS2010.4) }\end{array}$ & 15 & $45 \%$ & $70 \%$ & $32 \%$ & $58 \%$ & ICT \\
\hline $\begin{array}{l}\text { Strategy, Management, } \\
\text { and Acquisition } \\
\text { (IS2010.7) }\end{array}$ & 10 & $30 \%$ & $29 \%$ & $16 \%$ & $53 \%$ & $\begin{array}{l}\text { Mgmt. of IS \& } \\
\text { Services }\end{array}$ \\
\hline $\begin{array}{l}\text { Enterprise Architecture } \\
\text { (IS2010.3) }\end{array}$ & 2 & $6 \%$ & $17 \%$ & $14 \%$ & Up to 50\% & No single category \\
\hline
\end{tabular}

Overall, Systems Analysis \& Design (IS2010.6), Data \& Information Management (IS2010.2), Foundations of IS (IS2010.1), and IS Project Management (IS2010.5) have common and accepted units of delivery that are core to the vast majority of programs. Along with Fundamentals of Programming, these are the big 5 of the undergraduate IS curriculum.

All three bodies, the ACM/AIS [14], BCS [3] and ACS [1] have a requirement for nontechnical skills variously called foundational knowledge and skills (ACM/AIS), transferable skills (BCS) and professional skills (ACS). These appear not to have been addressed in other studies, but in the Australian context, the influence of the ACS is evident, with the prevalence

3 These do not align well with ACM/AIS Model Curriculum.

4 This subject area includes programming and project management. 
of professional skills units, and of specific capstone projects, equally divided between one and two semester units. Some programs offer actual industry placements, generally in a competitive selection process, but the majority aim to provide an authentic as possible industry experience without students being embedded in workplaces.

Within Australia, the ACS has a strong requirement of IT programs to include professional skills, such as ethical frameworks and the professional code of conduct, communication and teamwork skills. Almost a half of programs (15 of 33) required a general professional skills unit that included ethics. Fifteen (15) programs embed or integrate these topics into multiple subject areas across the curriculum, but others provide units that target particular professional skills such as communication (8), problem solving (3), collaboration and teamwork (1), and working in industry (1). Some programs had more than one professional skills unit.

Similar to professional skills, capstone activity show up more clearly in this study. Again, capstone activity is a clear requirement for ACS accreditation. Twenty-two (22) of the 33 programs include one or two semester-unit projects. Four (4) programs require industry experience, and 2 mandate a capstone subject, where integration of topics is covered in a more traditional classroom format. Five (5) embed or integrate capstone requirements into other subject areas.

\section{Conclusion}

This project has provided a comprehensive, detailed and current picture of undergraduate IS degree programs in Australia. This alone will be useful to those who manage and develop IS programs. Overall, the picture paints a high level of agreement between Australian and US undergraduate IS majors. Alignment with the ACM/AIS IS2010 model curriculum in Australia is on par, if not higher than that of the US. Systems Analysis \& Design (IS2010.6), Data \& Information Management (IS2010.2) Foundations of IS (IS2010.1), IS Project Management (IS2010.5) along with have Fundamentals of Programming have common and accepted units of delivery that are core to the vast majority of programs. In the US data communications and networking is most likely to be delivered through IS2010 IT Infrastructure (IS2010.4) while in Australia a dedicated Data Communication unit is more likely to be required core.

This picture also reveals considerable diversity of topics, more than that found in the US studies. 648 distinct units were mapped into 140 distinct subject areas across the Australian IS curriculum, suggesting a considerable range in packaging of topics, possibly attempts to address niche or emerging areas of the discipline.

It would also seem that there are some differences that stem from the nature of the academic organisational unit that manages an IS program. Those in technology-based units may gain a broader, but more technical education than those based in business for example.

This study raises questions about the packaging of topics or subject areas in the IS2010 model core. Clearly, Systems Analysis \& Design (IS2010.6), Data \& Information Management (IS2010.2), Fundamentals of IS (IS2010.1) and IS Project Management (IS2010.5) are widely accepted sets of topics. IT Infrastructure (IS2010.4) and Strategy, Management, and Acquisition (IS2010.7) are less common and Enterprise Architecture (IS2010.3) is rarely required as a distinct subject, at least in undergraduate programs. Outside of the IS2010 core, Fundamentals of Programming is at least as important as IT Infrastructure (IS2010.4) and Strategy, Management, and Acquisition (IS2010.7).

Further studies could address graduate IS degrees, examining the packaging of topics and the effects accrediting bodies may have on the core topic components.

\section{Acknowledgements}

The authors gratefully acknowledge the financial assistance of the Australasian Council of Professors and Heads of Information Systems (ACPHIS) in conducting this project, and the help of all of those IS program coordinators who participated in the consultation process. 


\section{References}

1. ACS: The ICT Professional Body of Knowledge Professional Standards Board. Australian Computer Society (2013)

2. Avison, D., Elliot, S.: Scoping the Discipline of Information Systems. published In: King, John L., Lyytinen, K. (eds.) Information Systems: The State of the Field, John Wiley and Sons, Ltd. (2006)

3. BCS: Guidelines on course accreditation: Information for universities and colleges. British Computer Society (2018).

4. Bell, C., Mills, R., Fadel, K.:An Analysis of Undergraduate Information Systems Curricula: Adoption of the IS2010 Curriculum Guidelines. In: Communications of the Association for Information Systems, Vol. 32 Article 2 (2013)

5. EC: e-Skills for ICT Professionalism: Creating a European Foundational ICT Body of Knowledge, European Commission (2014)

6. EC: The European Foundational ICT Body of Knowledge, Version 1.0, European Commission (2015)

7. Gable, G., Gregor, S., Clarke, R., Ridley, G., Smyth, R. (eds.): The Information Systems Academic Discipline in Australia, ANU E Press (2008)

8. Hwang, D., Ma, Z., Wang, M.: The Information Systems Core: A Study from the Perspective of IS Core Curricula in the US. In: Proceedings of the Information Systems Educators Conference, Baltimore, Maryland USA (2014)

9. Hwang, D., Ma, Z., Wang, M.: The Information Systems Core: A Study from the Perspective of IS Core Curricula. In the US IS Education Journal, 13(6), 27-34 (2015)

10. Reynolds, John H., Ferguson, Roger C., Leidig, Paul M.: A Tale of Two Curricula: The Case for Pre-requisites in the IS Model Curriculum. In: Proceedings of the EDSIG Conference (2015) Conference on Information Systems and Computing Education, Wilmington, North Carolina USA (2015)

11. Ridley, G.: Characterising Information Systems in Australia: A Theoretical Framework. In: Australasian Journal of IS, Vol 14, November (2006)

12. SFIA: SFIA6: The Complete Reference Guide, SFIA Foundation (2015)

13. Stefanidis, A., Fitzgerald, G.: Information Systems Curriculum in UK Universities. In: Journal of Information Systems Education Vol. 21 Issue 4 (2010)

14. Topi, H., Valacich, Joseph S., Wright, Ryan T., Kaiser, K., Nunamaker Jr., Jay F., Sipior. Janice C., de Vreede, G-J: IS2010: Curriculum Guidelines for Undergraduate Degree Programs in Information Systems. In: Communications of the Association for Information Systems. Vol. 26, Article 18 (2010)

15. Topi, H., Karsten, H., Brown, Sue A. , Cavallo, João A., Donnellan, B., Shen, J., Tan, Bernard C. Y., Thouin, Mark F.: "MSIS 2016 Global Competency Model for Graduate Degree Programs in Information Systems," Communications of the Association for Information Systems: Vol. 40 , Article 18 (2017)

16. UK QAA: Subject Benchmarking Statement, Computing, UK Quality Code for Higher Education (2016)

17. Yang, Samuel C.: The core curriculum information systems undergraduate programs: A survey of AACSB-accredited colleges in the United States. In: Journal of Education for Business, 91:5, 258-266 (2016) 